\title{
Design and Analysis of Impact Barriers
}

\author{
Tejaswi Sunkara ${ }^{1}$, U Sudhakar², Dayakar ${ }^{3}$ \\ ${ }^{1}$ PG Scholar (Cad - Cam), MLRITM Dundigal, Hyderabad, Telangana, India \\ ${ }^{2}$ Associate Professor (Cad - Cam), MLRITM Dundigal, Hyderabad, Telangana, India \\ ${ }^{3}$ Associate Professor (Cad - Cam), MLRITM Dundigal, Hyderabad, Telangana, India
}

\begin{abstract}
Textile honeycomb composites, with an array of hexagonal cells in the cross section, is a type of textile composites having the advantage of being light weight and energy absorbent over the solid composite materials. These structures are natural or manmade structures that have the geometry of a honeycomb to allow the minimization of the amount of used material to reach minimal weight and minimal material cost. The aim of this project is to investigate the influence of the geometric parameters on textile honeycomb composites on their mechanical performances under low velocity impact, which can be used to help designer control over the textile honeycomb composites. This project carries the comparison between hexagonal, square, triangular and cross triangular composite shapes for optimized inner core design based on FEA impact analysis to rectify the delamination problems occurring in honeycomb technology due to impacts.
\end{abstract}

Keywords: Impact Barriers, Solid Works, CAE model, Hyper mesh

\section{Introduction}

The Washington State Department of Transportation (WSDOT) uses traffic barriers to reduce the overall severity of collisions that occur when a vehicle leaves the traveled way. Consider whether a barrier is preferable to the recovery area it replaces. In some cases, installation of a traffic barrier may result in more collisions, as it presents an object that can be struck. Barriers are designed so that such encounters might be less severe and not lead to secondary or tertiary collisions. However, when impacts occur, traffic barriers are not guaranteed to redirect vehicles without injury to the occupants or additional collisions. Barrier performance is affected by the characteristics of the types of vehicles that collide with them. For example, motor vehicles with large tires and high centers of gravity are commonplace on our highways and they are designed to mount obstacles. Therefore, they are at greater risk of mounting barriers or of not being decelerated and redirected as conventional vehicles would be.

When barriers are crash-tested, it is impossible to replicate the innumerable variations in highway conditions. Therefore, barriers are crash-tested under standardized conditions. These standard conditions were previously documented in National Cooperative Highway Research Program (NCHRP) Report 350. These guidelines have been updated and are now presented in the Manual for Assessing Safety Hardware (MASH).

Barriers are not placed with the assumption that the system will restrain or redirect all vehicles in all conditions. They are placed with the assumption that under normal conditions, they might provide an improved safety condition for most collisions. Consequently, barriers should not be used unless an improved safety situation is likely. No matter how well a barrier system is designed.

\subsection{Literature Survey}

Xiaozhou Gong [1] Cellular solids such as sandwich panels have been used as advanced materials in aerospace, automobile and marine industries for decades due to their unique combination of properties derived from their cellular structures. Scientists and engineers have paid more and more attentions to cellular solids since new techniques for making ceramic and metallic foams have widened the range of manmade materials and the diversity of their applications. Textile reinforced honeycomb composite can be regarded as a kind of cellular solid due to its hollow core structure and as an innovative product, much interests have been drawn on it to find out its mechanical performance under various loading conditions. This chapter presents a literature review on cellular solids including textile honeycomb composites in the following aspects, which are classification, applications, mechanical and non-mechanical features of cellular solids honeycomb structure manufacturing techniques the mechanical performances of cellular solids under various impact conditions the energy absorption analysis of cellular solids the basic concept of three-dimensional (3D) fabrics and structural parameters for textile honeycomb composite the application of $3 \mathrm{D}$ honeycomb fabrics on personal protection equipment (PPE).

Thomas Jost[2] Using Finite Element (FEM) it is possible to show and predict the behavior of the vehicles structure during a crash test. To ensure good simulation results compared to the reality it is not only necessary to carryout built up the FE-model of the vehicle, but to simulate the real behavior of crash barrier. To meet this demand a new method for modeling and simulating crash barrier has been developed. This method is based on discrete beam elements to model aluminum honeycomb structure. The major advantage of this method is to possibility to show realistic local global deformation behavior of honeycomb structures.

\subsection{Project Aim and Objectives}

This project gives better shape for textile composite impact barriers by analyzing results using FEM based software COMSOL for impact analysis on honey comb box type and triangular and hexagonal models, Solid Works software to 


\section{International Journal of Science and Research (IJSR) \\ ISSN (Online): 2319-7064 \\ Index Copernicus Value (2013): 6.14 | Impact Factor (2014): 5.611}

model 3D models of honeycomb structures. This is going to help in finding out a alternative geometric shape which can be used as a replacement to the traditional hexagonal honeycomb structure and which can help in reducing the delimitation problem of honeycomb structure.

- Selection of different geometric structures for better inner cores

- Selection of different materials (composite fibers).

- Use of solid Works to prepare 3D models.

- Use of COSMOS to perform analysis.

- Comparison of results of different geometric structures with traditional hexagonal honeycomb structure.

- To provide a best suitable alternative for traditional hexagonal honeycomb structure.

\section{Barrier Design}

When selecting a barrier, consider the flexibility, cost, and maintainability of the system. It is generally desirable to use the most flexible system possible to minimize damage to the impacting vehicle and injury to the vehicle's occupant(s). However, since no rigid systems sustain more damage during an impact, the exposure of maintenance crews to traffic might be increased with the more frequent need for repairs.

- Maintenance costs for concrete barrier are lower than for other barrier types. In addition, deterioration due to weather and vehicle impacts is less than most other barrier systems.

- Unanchored precast concrete barrier can usually be realigned or repaired when moved from its alignment. However, heavy equipment may be necessary to reposition or replace barrier segments.

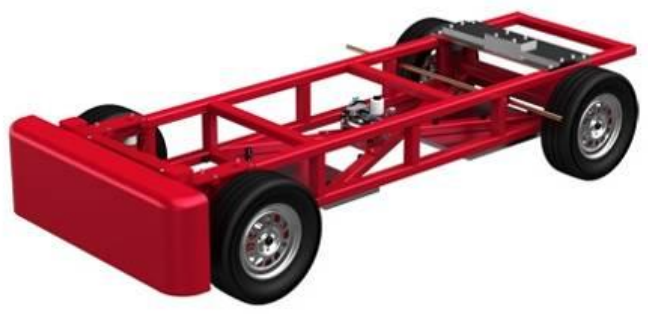

Figure 2.1: Frame Structure of a Fore Wheel Drive

When designing a barrier for use on a Scenic Byway, consider barriers that are consistent with the recommendations in the associated corridor management plan (if one is available). Contact the region Landscape Architect or the Scenic Byways Coordinator in the HQ Highways and Local Programs Office to determine whether the project is on such a designated route. Low-cost options, such as using weathering steel beam guardrail or cable barrier, might be feasible on many projects. Higher cost options, such as steel-backed timber rail and stone guard walls, might necessitate a partnering effort to fund the additional costs. Grants might be available for this purpose if the need is identified early in the project definition phase.

\subsection{Barrier Deflections}

Expect all barriers except rigid barriers (such as concrete bridge rails) to deflect when hit by an errant vehicle. The amount of deflection is primarily dependent on the stiffness of the system. However, vehicle speed, angle of impact, and weight also affect the amount of barrier deflection. For flexible and semi rigid roadside barriers, the deflection distance is designed to help prevent the impacting vehicle from striking the object being shielded. For un-restrained rigid systems (unanchored precast concrete barrier), the deflection distance is designed to help prevent the barrier from being knocked over the side of a drop-off or steep fill slope. In some locations where deflection distance is limited, anchor precast concrete barrier. Unless the anchoring system has been designed to function as a rigid barrier, some movement can be expected and repairs may be more expensive. Use of an anchored or other deflecting barrier on top of a retaining wall without deflection distance provided requires approval. The deflection distance for un-anchored concrete barrier is the minimum measurement from the back edge of the barrier to the drop-off or slope break.

\subsection{Composite Material}

For the specific carbon and glass fiber based composite materials often referred to loosely as 'composites 'Composites are formed by combining materials together to form an overall structure that is better than the individual components.

\begin{tabular}{|l|l|}
\hline High strength-to-weight ratio & Corrosion Resistance \\
\hline Wear Resistance & Stiffness \\
\hline Fatigue Life & $\begin{array}{l}\text { Temperature-Dependent } \\
\text { Behavior }\end{array}$ \\
\hline Thermal Insulation & Thermal Conductivity \\
\hline Acoustical Insulation & $\begin{array}{l}\text { Low-Electrical } \\
\text { Conductivity }\end{array}$ \\
\hline Visual Attractiveness & Radio translucent \\
\hline
\end{tabular}

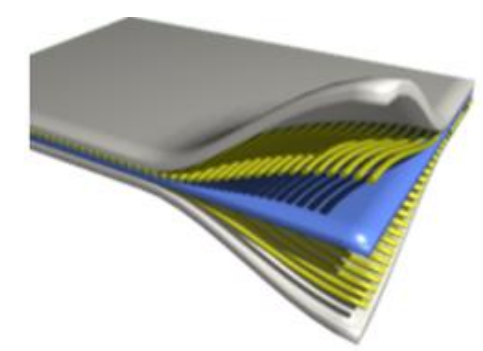

Figure 2.3.1 Traffic Barrier locations on Slopes

Composite materials (also called composition materials or shortened to composites) are materials made from two or more constituent materials with significantly different physical or chemical properties that when combined, produce a material with characteristics different from the individual components. The individual components remain separate and distinct within the finished structure. The new material may be preferred for many reasons: common examples include materials which are stronger, lighter or less expensive when compared to traditional materials.

Typical engineered composite materials include:

- Composite building materials such as cements, concrete

- Reinforced plastics such as fiber-reinforced polymer

- Metal composites

- Ceramic composites(composite ceramic and metal matrices)

\section{Volume 4 Issue 11, November 2015}




\section{International Journal of Science and Research (IJSR) \\ ISSN (Online): 2319-7064 \\ Index Copernicus Value (2013): 6.14 | Impact Factor (2014): 5.611}

Composite materials are generally used for buildings, bridges and structures such as boat hulls, swimming pool panels, race car bodies, shower stalls, bathtubs, and storage tanks, imitation granite and cultured marble sinks and counter-tops. The most advanced examples perform routinely on spacecraft in demanding environments.

\subsection{Composite Advantages}

Composites have actually been in use for thousands of years. Adobe bricks were made using a composite of mud and straw. It is the combination of the physical properties of each material that gives the composite material many of its physical characteristics. Today's advanced composites, like carbon fiber, bring together combined properties we've come to know - lightweight, strong, durable and heat-resistant. Today, the benefits of components and products designed and produced in composite materials - instead of metals, such as aluminum and steel - are well recognized by many industries. Some of the advantages include:

Weight reduction using composites has created a huge market demand in automotive, industrial, aerospace and other industries. None is more visible than the commercial airline industry. Due to the high cost of aviation fuel, aircraft manufacturers are now competing based upon their aircraft's fuel efficiency. In recent years, these manufacturers have turned to the use of light weight composites in their designs without having to compromise strength and durability for almost every component of their aircraft. The resulting weight reduction that is realized by using composite materials translates into considerable cost savings in terms of fuel.

In aircraft design carbon fiber composites, hybrid composites, and composite reinforced plastics are being used in more and more sections of the aircraft, including:

- Engine Nacelles

- Seating and Interior Finishes

- Horizontal and Vertical Stabilizers

- Rudders

- Ailerons

- Floor Beams

- Elevators

- Front and Main Landing Gear Doors

- Wing to Fuselage Fairings

- Full Fuselage and Wing Assemblies

\subsection{Epoxy Solution}

To add in a layer of glass, or alternatively make sure to pepper with micro spheres to provide enough insulation to prevent galvanic corrosion and delamination.

Four compounds were used to improve adhesion between carbon fibers and an epoxy matrix. Triglycidylisocyanurate (TGIC) and 3-glycidoxy-propyl-triethoxysilane (EPS) contained reactive epoxy groups, while N-(3trimethoxysilane-propyl) ethylene Damien (AMS) a primary and a secondary amino group. The fourth coupling agent was 4, 4'diphenylmethane-diisocianate (MDI). The interaction of the fiber and the coupling agents was studied by dissolution experiments. Chemical reactions taking place on the surface of the fiber were followed by FTIR spectroscopy. Inter-facial shear stress determined by fragmentation was used for the characterization of matrix/fiber adhesion. Besides coupling to the surface, EPS, AMS and MDI formed a polymer layer on the surface, but TGIC also entered into secondary reactions during the treatment. Both the type and the amount of the coupling agent affect strongly inter facial adhesion, which is determined by the thickness and properties of the formed coupling agent layer. The combination of dissolution experiments with the fragmentation test yields valuable information about the processes taking place on the surface of the fiber; facilitate the selection of the best coupling agent, as well as the development of surface treatment technology.

\section{Honeycomb Structures}

Honeycomb structures are natural or man-made structures that have the geometry of a honeycomb to allow the minimization of the amount of used material to reach minimal weight and minimal material cost. The geometry of honeycomb structures can vary widely but the common feature of all such structures is an array of hollow cells formed between thin vertical walls. The cells are often columnar and hexagonal in shape. A honeycomb shaped structure provides a material with minimal density and relative high out-of-plane compression properties and out-of plane shear properties.

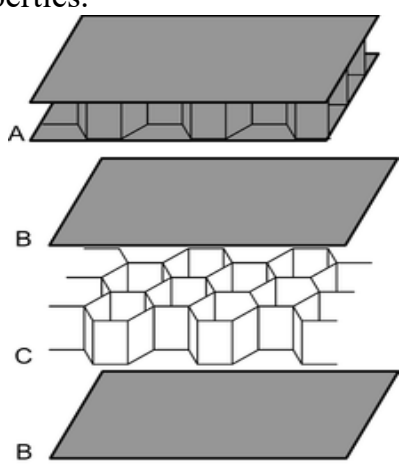

Figure 3.1 A composite sandwich panel (A) with honeycomb core $(\mathrm{C})$ and face sheets $(\mathrm{B})$

Man-made honeycomb structural materials are commonly made by layering a honeycomb material between two thin layers that provide strength in tension. This forms a platelike assembly. Honeycomb materials are widely used where flat or slightly curved surfaces are needed and their high strength-to-weight ratio is valuable. They are widely used in the aerospace industry for this reason, and honeycomb materials in aluminum, fiberglass and advanced composite materials have been featured in aircraft and rockets since the 1950s. They can also be found in many other fields, from packaging materials in the form of paper-based honeycomb cardboard, to sporting goods like skis and snowboards.

\subsection{Applications}

- They are widely used in the aerospace industry.

- They are widely used in the aerospace industry. 


\section{International Journal of Science and Research (IJSR) \\ ISSN (Online): 2319-7064}

Index Copernicus Value (2013): 6.14 | Impact Factor (2014): 5.611

- From packaging materials in the form of paper-based honeycomb cardboard, to sporting goods like skis and snowboards.

- Used as front barriers in heavy vehicles.

- Used in Automobile industries.

\subsection{Advantages}

- Very low weight

- High stiffness

- Durability

- Production cost savings

\section{Problem Description}

Most of the vehicles are using sheet metal or solid type of impact barriers which offer's good resistance for primary impact but most of the impact force is transferred on the vehicle, at present most of the vehicles are using honey comb structures, in honeycomb problem of delamination is observed due to impacts. Due to this problem they are replacing barrier even after a small impacts.

\section{Following are the main objectives:}

This project gives better shape for textile composite impact barriers by analyzing results using FEM based software COMSOL for impact analysis on honey comb box type and triangular and hexagonal models, Solid Works software to model 3D models of honeycomb structures. This is going to help in finding out a alternative geometric shape which can be used as a replacement to the traditional hexagonal honeycomb structure and which can help in reducing the delimitation problem of honeycomb structure.

- Selection of different geometric structures for better inner cores

- Selection of different materials (composite fibers).

- Use of solid Works to prepare 3D models.
- Use of COSMOS to perform analysis.

- Comparison of results of different geometric structures with traditional hexagonal honeycomb structure.

- To provide a best suitable alternative for traditional hexagonal honeycomb structure.

\section{Research Methodology}

\section{Selection of different geometric structures for better inner cores:}

It is important to understand the stiffness and strength performances of honeycombs when they are used in loadbearing structure. Gibson and Ash-by (1997) specified that generally, if a honeycomb is compressed in-plane that is the plane along X1 and X2 direction in Figure 3, the cell wall at first bend, giving linear elastic deformation. Beyond a critical strain, the cells collapse by elastic buckling, plastic yielding, creep or brittle fracture, depending on the nature of the cell wall material. Cell collapse ends once the opposing cell walls begin to touch each other and as the cells closed up, the stiffness of the structure increases rapidly. When the loading is along out-of-plane direction, which is along X3 direction in Figure 3, the stiffness and strength are much higher because they require extra axial extension or compression of the cell walls.

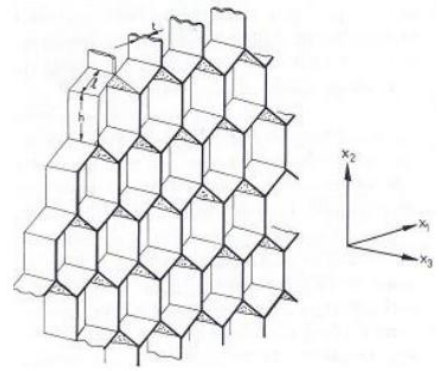

Figure 5.1: Honeycomb structure with hexagonal cells
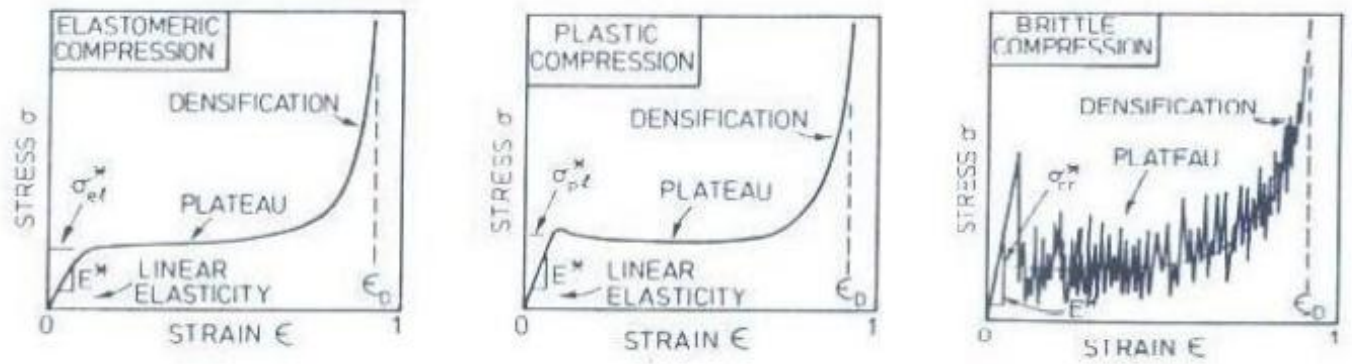

Graph 5.2 Stress-Strain Curves for Cellular Solid

Modeling of Traditional hexagonal cross-sectioned impact barrier Honeycomb Structure using Solid Works This impact barrier is used for 10 to 16 ton capacity trucks; it is placed infront of bumper and is connected with chassis

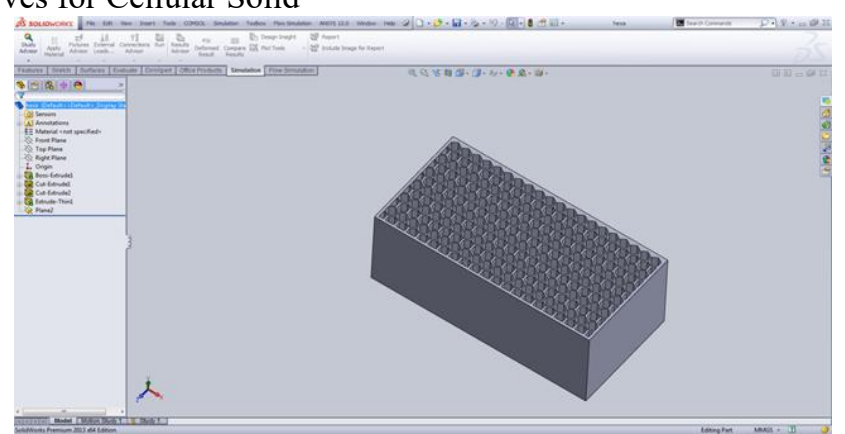

Figure 5.2.1: Traditional hexagonal cross-sectioned impact barrier Honeycomb Structure 


\section{International Journal of Science and Research (IJSR) \\ ISSN (Online): 2319-7064}

Index Copernicus Value (2013): 6.14 | Impact Factor (2014): 5.611
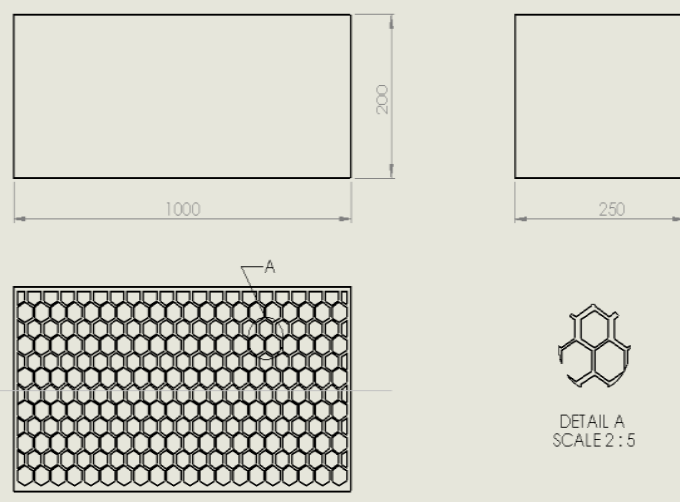

Figure 5.2.1: Drafting of hexagonal cross-sectioned impact barrier(The above shape is the traditional structure of impact barrier)

Modeling of Square cross-sectioned impact barrier Honeycomb Structure using Solid Works

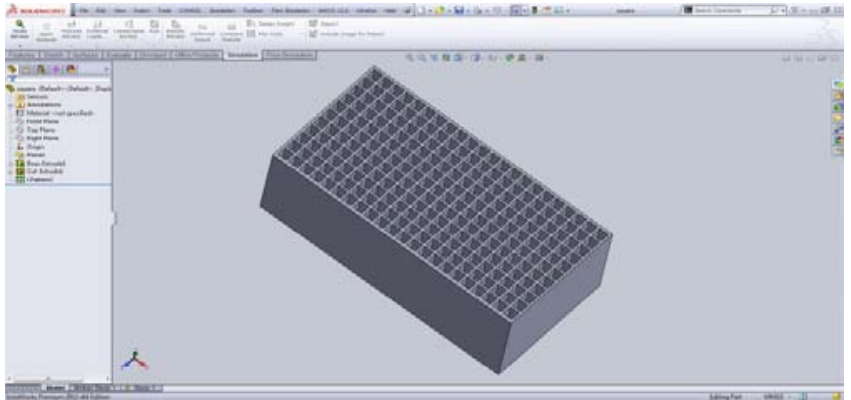

Figure 5.2.2: Square cross-sectioned impact barrier (Created using extrude and cut operations with individual sketches in solid works)
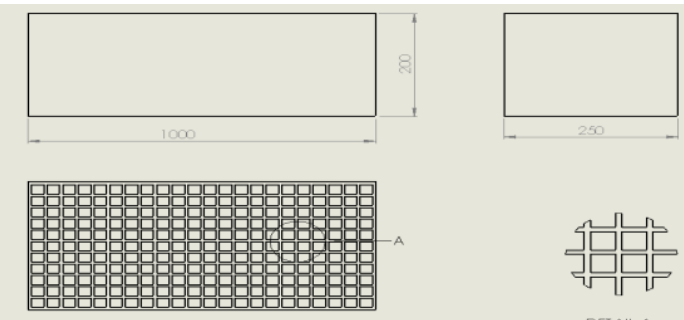

Figure 5.2.2: Drafting of square cross-sectioned impact barrier

(The above images shows the new geometry shape)

\section{Modeling of Triangular cross-sectioned impact barrier \\ Honeycomb Structure using solid works}

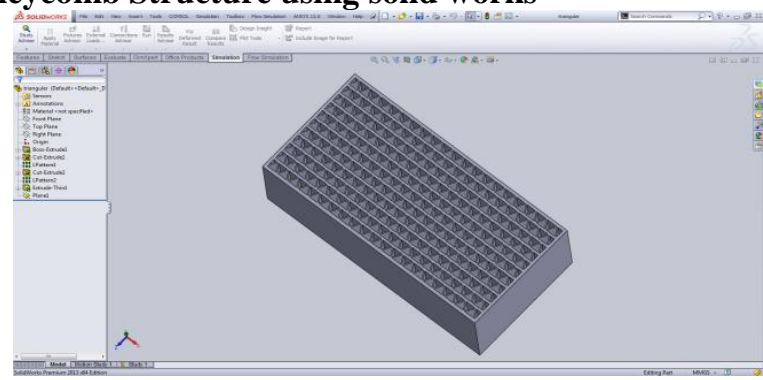

Figure 5.2.3: Triangular cross-sectioned impact barrier (Created using extrude and cut operations with individual sketches in solid works)
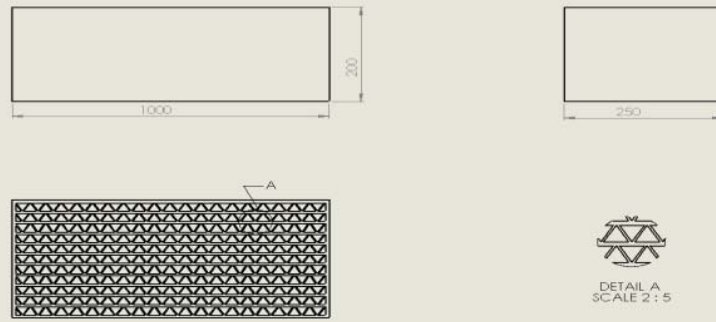

Figure 5.2.3: Drafting of triangular cross-sectioned impact barrier (The above images shows the new geometry shape)

Modeling of cross-triangular cross-sectioned impact barrier Honeycomb Structure using Solid Works

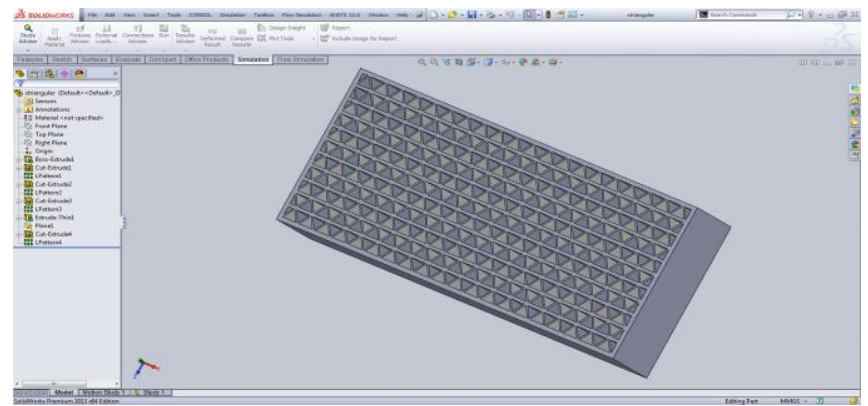

Figure 5.2.4: Cross-triangular cross-sectioned impact barrier (Created using extrude and cut operations with individual sketches in solid works)
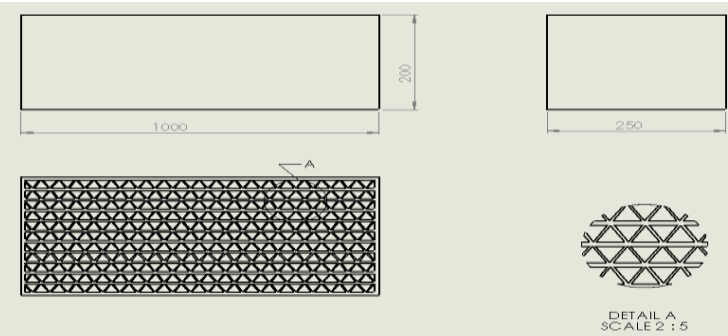

Figure 5.2.4: Drafting of cross-triangular cross-sectioned impact barrier (The above images shows the new geometry shape)

\subsection{Load Conditions}

When barriers are crash-tested, it is impossible to replicate the innumerable variations in highway conditions. Therefore, barriers are crash-tested under standardized conditions. These standard conditions were previously documented in National Cooperative Highway Research Program (NCHRP) Report 350. These guidelines have been updated and are now presented in the Manual for Assessing Safety Hardware (MASH).

As per the above discussion we are going to conduct analysis at speed of $250 \mathrm{kmph}=69.44 \mathrm{M} / \mathrm{S}$

Impact analysis of square s2-glass structure Square (s2-glass) 


\section{International Journal of Science and Research (IJSR) \\ ISSN (Online): 2319-7064}

Index Copernicus Value (2013): 6.14 | Impact Factor (2014): 5.611

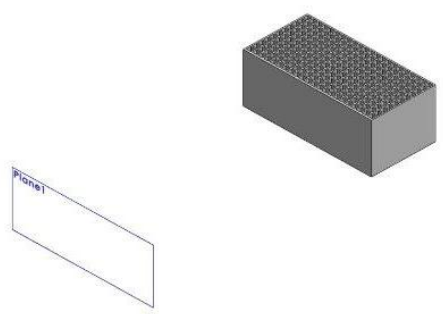

Figure 5.3.1: Solid Model of SQUARE S2-Glass

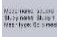

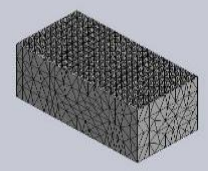

Figure 5.3.2: Meshed Model of SQUARE S2-Glass 대란...

Figure 5.3.3: Von misses stress value, $\mathrm{Min}=$ $3.1917 \mathrm{~N} / \mathrm{mm}^{\wedge} 2(\mathrm{MPa}), \mathrm{Max}=281.863 \mathrm{~N} / \mathrm{mm}^{\wedge} 2(\mathrm{MPa})$

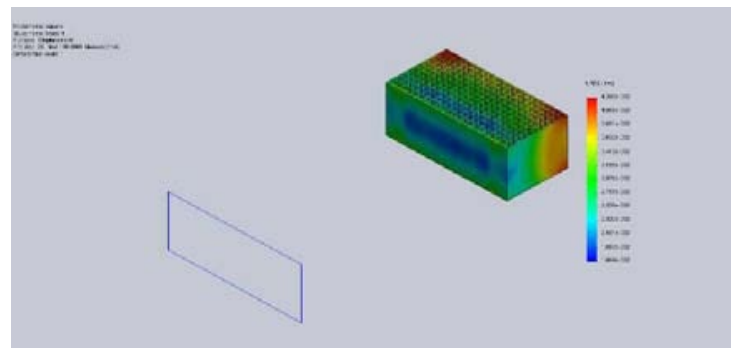

Figure 5.3.4: Displacement value, $\operatorname{Min}=0.0166425 \mathrm{~mm}$, $\operatorname{Max}=0.0428777 \mathrm{~mm}$

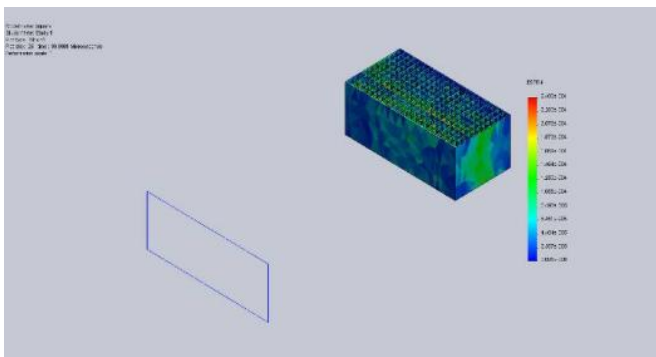

Figure 5.3.5: Strain Value, $\operatorname{Min}=3.09523 \mathrm{e}-006, \operatorname{Max}=$ 0.000248751

Impact analysis of triangular s2-glass structure Triangular (s2-glass)
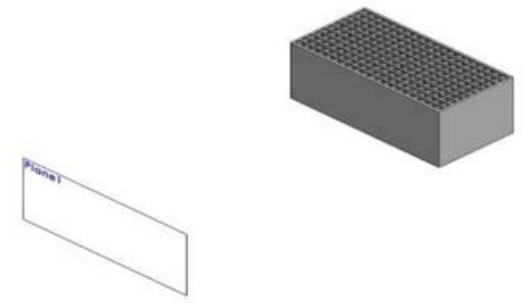

Figure 5.3.6: Solid model of TRIANGULAR (s2-glass)

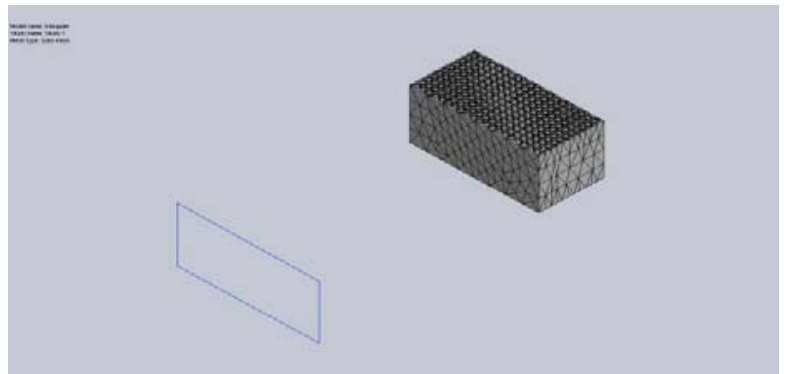

Figure 5.3.7: Meshed model of TRIANGULAR- S2-Glass

Table: Results

\begin{tabular}{|c|c|c|c|c|}
\hline \multirow{3}{*}{ Shape } & Material & $\begin{array}{r}\text { Von-misses Stress In } \\
(\mathrm{N} / \mathrm{mm} 2)\end{array}$ & $\begin{array}{r}\text { Displaceme } \\
\text { nt in (mm) }\end{array}$ & Strain \\
\hline \multirow{4}{*}{ Hexagonal } & E-Glass & 826.247 & 0.98144 & 0.0107664 \\
\cline { 2 - 5 } & S2- Glass & 3561.1 & 0.544576 & 0.00331992 \\
\cline { 2 - 5 } & Aluminum & 842.841 & 0.981015 & 0.0121315 \\
\hline \multirow{4}{*}{ Square } & E-Glass & 141.632 & 0.200035 & 0.00130533 \\
\cline { 2 - 5 } & S2- Glass & 281.863 & 0.042878 & 0.000248751 \\
\cline { 2 - 5 } & Aluminum & 131.796 & 0.199973 & 0.0015333 \\
\hline \multirow{3}{*}{ Cross-Triangular } & E-Glass & 138.738 & 0.175346 & 0.00133339 \\
\cline { 2 - 5 } & S2- Glass & 420.233 & 0.073327 & 0.000351508 \\
\cline { 2 - 5 } & Aluminum & 141.817 & 0.175295 & 0.00152341 \\
\cline { 2 - 5 } & E-Glass & 151.585 & 0.175132 & 0.00148002 \\
\cline { 2 - 5 } & S2- Glass & 414.289 & 0.054284 & 0.000378127 \\
\hline & Aluminum & 145.002 & 0.175229 & 0.00177581 \\
\hline
\end{tabular}

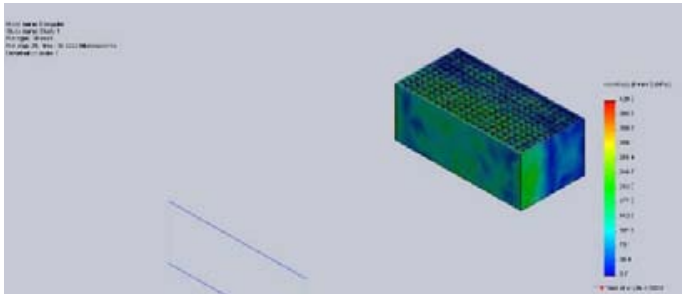

Figure 5.3.8: Von misses stress value, $\operatorname{Min}=3.71096$ $\mathrm{N} / \mathrm{mm}^{\wedge} 2(\mathrm{MPa}), \operatorname{Max}=420.233 \mathrm{~N} / \mathrm{mm}^{\wedge} 2(\mathrm{MPa})$

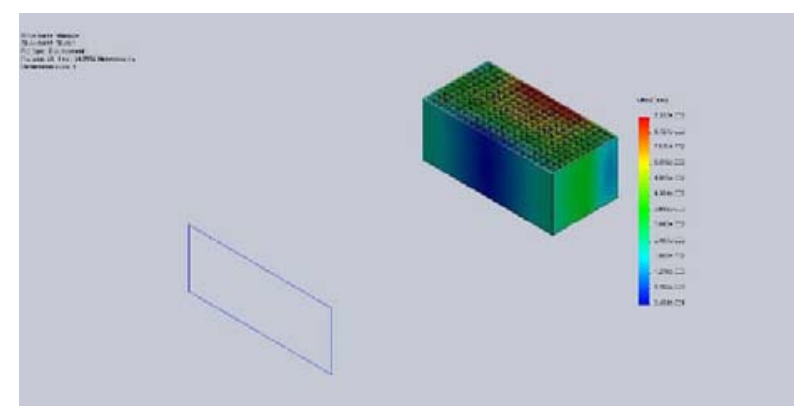

Figure 5.3.9: Displacement value, $\operatorname{Min}=0.0006454 \mathrm{~mm}$, $\operatorname{Max}=0.0733271 \mathrm{~mm}$ 


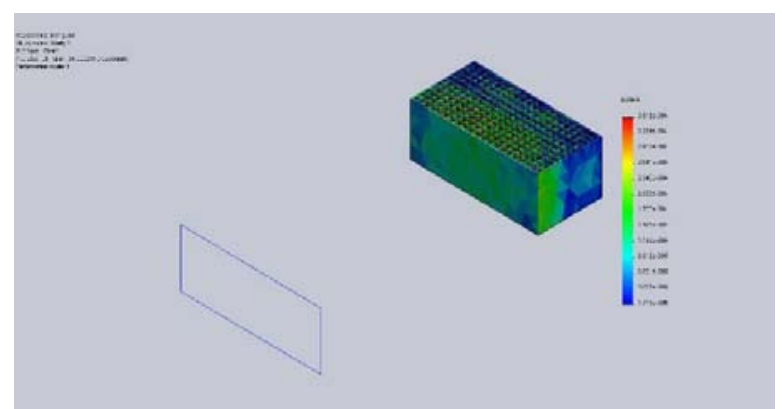

Figure 5.3.10: Strain value, $\operatorname{Min}=1.71599 \mathrm{e}-006, \operatorname{Max}=$ 0.000351508

\section{Conclusions}

This project thesis gives brief explanation about impact barriers and composite textile technology. As discussed earlier the honey comb textile impact barriers having delaminating problem. In this thesis different composite structures are validated to overcome the above said problem. Initially literature survey was done on impact barrier and textile structures, in the next step 3D models (honey comb, square, triangular and cross triangular) are prepared to carry out the impact test.

Impact test is conducted on honeycomb structure to evaluate the results. And also impact test is conducted on new structures to validate the designs.

Generally aluminum alloy is used to manufacture impact barrier and its core structure. This thesis also discuss about application FRP and CRF's.(epoxy's).

As per the analytical results obtained from impact analysis square type with s2-glass is the best replacement for honey comb textile technology.

\section{References}

[1] Investigation of different geometric structure parameter for honeycomb textile composites on their mechanical performance. A thesis submitted to the university of Manchester for the degree of Doctor of Philosophy in the Faculty of Engineering and Physical Sciences By Xiaozhou Gong.

[2] A New Method of Model Aluminum Honeycomb Based Crash barriers in Lateral and Front Load Cases by Thomas Jost, Thomas Heubrandtner, Charistian Ruff, Bernhard Fellner, Kompetenzzentrum-Das Virtuelle Fahrzeug Forschugsgesells chaftmbH, Graz, Austria.

[3] Development of the Advanced Finite Element Model for Impact Barrier by MehrdadAsadi (m.asadi@cellbond.com) Cellbond Composites Ltd. (UK), Brian Walker ARUP (UK), Hassan Shirvani, Anglia Ruskin University (UK).

[4] Experiences in reverse-engineering of a "finite element automobile crash model Z.Q. Chenga, J.G. Thackera, W.D. Pilkeya, W.T. Hollowellb, S.W. Reagana, E.M. Sievekaa. 